\title{
Young woman who presents with shortness of breath
}

\author{
Marcela De La Hoz Polo ${ }^{1}$ Monica Khanna ${ }^{1} \cdot$ Miny Walker $^{1}$
}

Published online: 29 October 2016

(C) ISS 2016

\section{Diagnosis}

Fibrodysplasia ossificans progressiva.

The chest radiograph of the chest demonstrates mature heterotopic ossification in the right latissimus dorsi muscle and tendon and in the soft tissues around each scapulae and bilateral ribs, with bone bridging probably across the right scapulothoracic joint with secondary reduced volume of the right hemithorax. The foot radiograph demonstrates a monophalageal great toe, a pathognomic abnormality of patients with this fatal disease (Figs. 1 and 2).

\section{Discussion}

Fibrodysplasia ossificans progressiva (FOP), also known as myositis ossificans progressiva and fibrositis ossificans progressiva, is a severely disabling heritable disorder of connective tissue characterized by progressive heterotopic ossification (HO) that forms qualitatively normal bone in characteristic extraskeletal sites, such as muscle, ligaments, and soft tissue, after minor trauma [1]. This condition is associated with congenital malformations of the extremities, most specifically malformed great toes. FOP is very rare, with a worldwide prevalence of approximately one case in 2 million individuals. No ethnic, racial, or geographic predisposition has

The case presentation can be found at doi: 10.1007/s00256-016-2511-7

Marcela De La Hoz Polo

marcela.delahozpolo@imperial.nhs.uk; mdelahozpolo@gmail.com

1 Radiology Department, St Mary's Hospital, Imperial College Healthcare NHS Trust, Praed Street, London W2 1NY, UK been described [1]. Most cases are the result of spontaneous new mutation of the gene encoding activin receptor $1^{\text {a }}$ (ACVR1) a bone morphogenetic protein (BMP) type 1 receptor signaling endochondral ossification. The genetic transmission may be also in an autosomal dominant pattern $[2,3]$. The mean duration of survival is 40 years [4].

Children affected by this disease appear normal at birth except for congenital malformations of the great toe [1]. The malformations involving the great toe include hallux valgus, hypoplasia, malformed first metatarsal, synostosis, and monophalangism. The definitive diagnosis of FOP can be made by simple clinical evaluation that associates the appearing soft tissue lesions in a child with malformed great toes [3]. Patients succumb to progressive waves of ectopic osteogenesis that transform the body's soft tissue connective tissues into an armament-like encasement of bone [3]. Clinically, the disease is characterized by episodes of acute pain, followed by the appearance of subcutaneous nodules (flare-ups) that evolve to ossify the soft tissues (muscles, ligaments, fascia, tendons). Some studies have shown the importance of pre-osseous lesions in the early diagnosis of FOP. These lesions have been described as areas of diffuse soft tissue swelling on MR images, which exhibit low T1 and high T2 signal, with contrast enhancement, in the muscles, intermuscular planes, subcutaneous tissue, or along the fascial planes without infiltrating into the surrounding muscles [5-7]. In contrast to most neoplasms, FOP pre-osseous lesions appear suddenly and then change size and shape rapidly, often in a matter of hours. The association of "malformed toes and soft tissue swellings" has been reported as features for early diagnosis of FOP in the absence of heterotopic ossifications, promptly preventing dangerous and unnecessary procedures that can cause catastrophic lifelong disability to the patients [7]. 


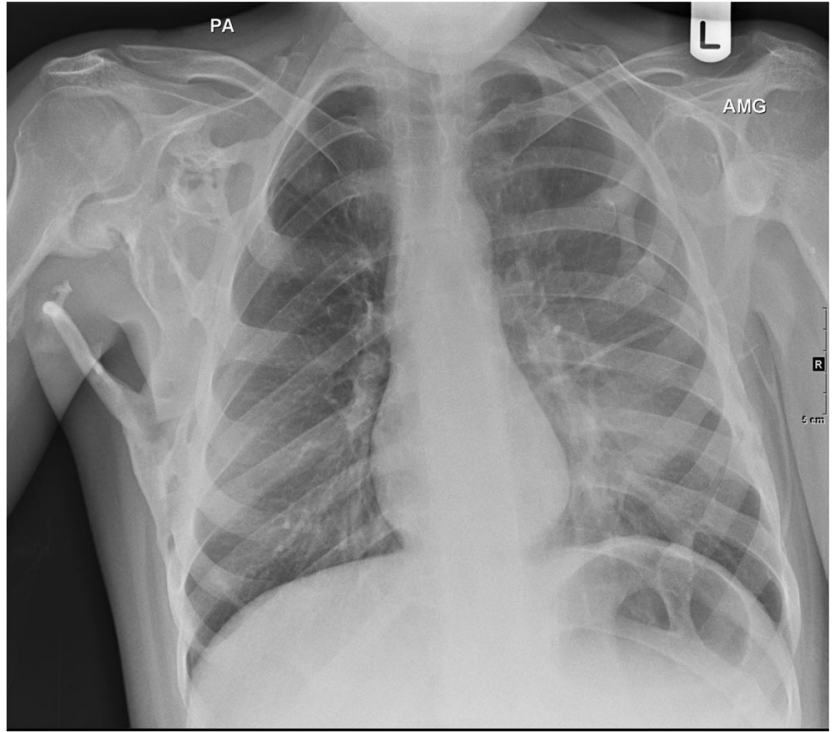

Fig. 1 Frontal chest radiograph

The disease occurs first in the dorsal, axial, cranial, and proximal regions of the body and is later seen in the ventral, appendicular, caudal, and distal regions [3, 8]. The diaphragm, tongue, extraocular, cardiac, and smooth muscles are not involved [4]. In addition to malformed great toes, early development anomalies are observed in the cervical spine, including large posterior elements, tall narrow vertebral bodies, and fusion of the facet joints between $\mathrm{C} 2$ and $\mathrm{C} 7$. Rotatory

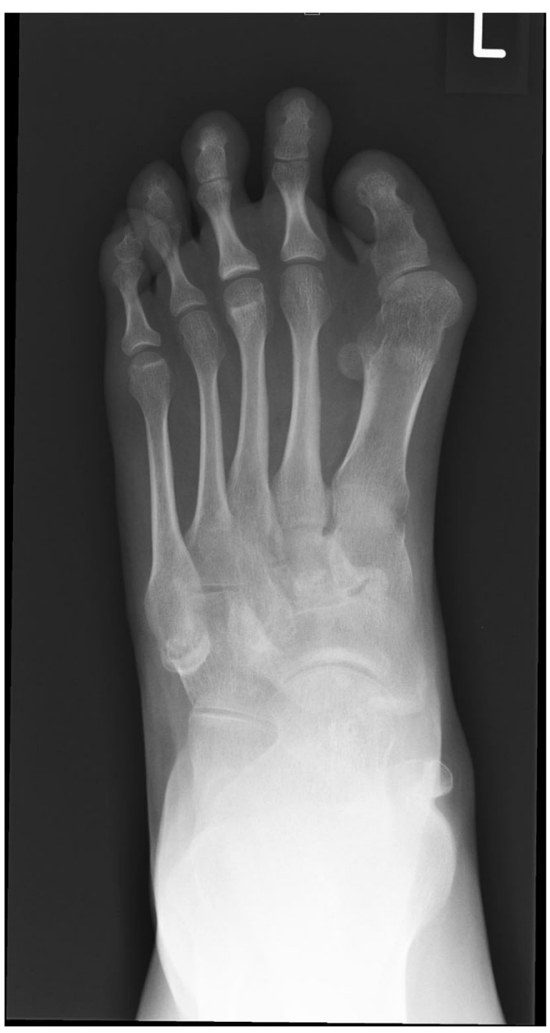

Fig. 2 Frontal radiograph of the left foot kyphoscoliosis of the spine is a late complication of the disease and is the result of unilateral osseous bridge along the spine prior to skeletal maturity. Other common skeletal manifestations include short thumbs, proximal medial tibial osteochondromas, neurosensory hearing loss, conductive hearing loss due to middle ear ossification, and short and broad femoral necks [3-5].

Simple stress factors, as a low-energy trauma, intramuscular injections, simple contusions, or viral infections may trigger the cascade of events [8]. Surgical resection of HO leads to explosive new bone formation $[9,10]$. As HO progresses, range of motion is progressively lost, leading to nearcomplete immobility.

Later clinical complications such as ankylosis of the temporomandibular joints lead to malnutrition. Due to the ankylosis of the costovertebral joints, ossification of intercostal muscles, paravertebral muscles, and aponeurosis, these patients are at risk of developing thoracic insufficiency syndrome, which is a life-threatening complication characterized by right-sided heart failure and pneumonia [3].

So far, no effective treatment method has been developed for FOP. Investigational therapies include antiangiogenic agents, retinoic acid receptor gamma-selective agonist, inhibitor RNA (RNAi) and signal transduction inhibitors (STIs) designated to block specifically the receptor ALK2. Non-steroidal anti-inflammatory medications, cox-2 inhibitors, leukotriene inhibitors, and mast cell stabilizers are useful anecdotally in managing clinical symptoms, but to date there is no proven efficacy with any therapy in altering the natural history of the disease. Therefore, early diagnosis and minimizing the trigger factors causing disease progression such as immunizations, bruises, falls, or viral illnesses, are crucial in these patients. Clinical management remains symptomatic $[3,5,11]$.

Since the most famous patient with FOP, Harry Raymond Eastlack, bequeathed his body to medical and scientific research back in 1973, much of what is known about this mysterious disease comes directly from study of his donated remains, but there is still more to be discovered.

\section{Compliance with ethical standards}

Conflict of interest The authors declare that they have no conflicts of interest.

\section{References}

1. Pignolo RJ, Shore EM, Kaplan FS. Fibrodysplasia ossificans progressiva: clinical and genetic aspects. Orphanet J Rare Dis. 2011;6(1):80.

2. Lakkireddy M, Chilakamarri V, Ranganath P, Arora AJ, Vanaja MC. Clinical and genetic analysis of fibrodysplasia ossificans 
progressiva: a case report and literature review. J Clin Diagn Res. 2015;9(8):1-3.

3. Pignolo RJ, Shore EM, Kaplan FS. Fibrodysplasia ossificans progressiva: diagnosis, management, and therapeutic horizons. Pediatr Endocrinol Rev. 2013;10(2):437-48.

4. Önal M, Bajin MD, Yılmaz T. Fibrodysplasia ossificans progressiva: a case report. Turk J Pediatr. 2014;56(5):561-4.

5. Lin FY, Lin CH, Shu G, Chen CK. Fibrodysplasia ossificans progressiva: initial presentation with a preosseous lesion of the scalp and its MRI appearance. Skeletal Radiol. 2016;45(7):991-6.

6. Hagiwara H, Aida N, Machida J, Fujita K, Okuzumi S, Nishimura G. Contrast-enhanced MRI of an early preosseous lesion of fibrodysplasia ossificans progressiva in a 21-month-old boy. AJR Am J Roentgenol. 2003;181(4):1145-7.
7. Kaplan FS, Xu M, Glaser DL, Collins F, Connor M, Kitterman J, et al. Early diagnosis of fibrodysplasia ossificans progressiva. Pediatrics. 2008;121(5):e1295-300.

8. Ortiz-Agapito F, Colmenares-Bonilla D. Quality of life of patients with fibrodysplasia ossificans progressiva. J Child Orthop. 2015;9(6):489-93.

9. Mishima K, Kitoh H, Haga N, Nakashima Y, Kamizono J, Katagiri $\mathrm{T}$, et al. Radiographic characteristics of the hand and cervical spine in fibrodysplasia ossificans progressiva. Intractable Rare Dis Res. 2014;3(2):46-51.

10. Kaplan FS. The skeleton in the closet. Gene. 2013;528(1):7-11.

11. Kaplan FS, Le Merrer M, Glaser DL, Pignolo RJ, Goldsby RE, Kitterman JA, et al. Fibrodysplasia ossificans progressiva. Best Pract Res Clin Rheumatol. 2008;22(1):191-205. 